\title{
Animal Models and Human Depressive Disorders
}

\author{
R. J. KATZ' \\ Mental Health Research Institute, Department of Psychiatry, \\ University of Michigan Medical Center, Ann Arbor, MI 48109
}

Received 15 February 1980

\begin{abstract}
KATZ, R. J. Animal models and human depressive disorders. NEUROSCI. BIOBEHAV. REV. 5(2) 231-246, 1981.Clinical depressive disorders are complex in presentation, dissimilar in origins and course, and often pleomorphic in character. An adequate understanding of their origins, biological substrates, and amenability to established and novel forms of therapy demands biological and social interventions which cannot always readily or ethically be carried out in a clinical setting. One useful complementary approach to clinical research utilizes preclinical models for laboratory investigations in parallel. The present paper reviews current approaches to modelling depression using animals, with particular emphasis upon phylogenetic constraints, systematic validity and reliability, and nosological limitations. Preclinical models are useful and necessary adjuncts for adequately understanding depression in humans. However, their utility remains a direct function of a continuing dialogue between clinical and laboratory research, and demands scrupulous observation and methodological rigor on the part of both clinicians and experimental researchers.
\end{abstract}

Animal models Depressive disorders

The behavior of animals has always fascinated man, whether he thinks he recognizes himself in them, or whether in the apparent differences of instincts he finds reasons to be proud of being human. From earliest times, those two tendencies can be distinguished: the one to compare animals to man in every respect (with no qualms, for example, about speaking of a moral sense in ants) and the other to regard animals as simple machines having nothing in common with man except a superficial resemblance (if the bitch of Malebranche yelps when one beats it, that is merely the speaking of ungreased wheels).

\section{Remy Chauvin Ethology} 1975

THE affective disorders increasingly have been the focus of psychiatric and psychobiological research. As Akiskal and McKinney [5] note, recent clinical and preclinical studies have gained in both methodological and conceptual sophistication, resulting in improved diagnosis and treatment. A number of factors have both contributed to and governed progress. One easily overlooked factor is the degree of communication between clinical and laboratory oriented scientists. It is imperative, on the one hand, for those attempting to approach depression using laboratory procedures to understand depression as a complex clinical entity. Experimenters divorced from clinical research may too easily confound syndromes which are only apparently and superficially similar. It is equally important, however, for clinicians to understand the degree to which laboratory procedures can accurately produce model pathological states. The present paper is directed at the second issue, i.e., the fundamental utility of laboratory models. A number of preclinical procedures have been utilized to model affective disorders and the present review attempts to categorize them, their phylogenetic boundaries, their validity and reliability, and finally their commonalities and differences.

Because laboratory models initially may be divided into a number of categories and subcategories, the present review will address each of these in course. One major division is between models devoted to drug screening and those devoted to more theoretical and phenomenological concerns. Within the former class are several related procedures, and within the latter two major procedures and several related variants. The initial sections of this review therefore first will discuss concerns common to all procedures, and then more pharmacologically oriented models. Subsequent sections then will focus on preclinical models of depression utilizing separation and depression, and unpredictable aversive stimulation.

\section{AN OVERVIEW OF ANIMALS MODELS THEIR UTILITY AND VALIDITY}

Preclinical models of psychiatric disorders may potentially serve a number of purposes. Unlike clinically observed behavioral disorders which may be heterogeneous with respect to type, life history, immediate precipitants, biochemical status, genetic load, and related factors, studies employing animals (chiefly mice, rats, cats, dogs, primates) may be better defined and potentially homogeneous on the above grounds. Thus any of these factors may be varied and independently examined. Additional considerations such as a

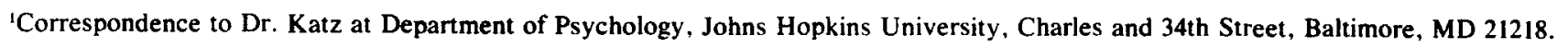


relatively short life span, allowing extensive longitudinal study both within and across generations, the relatively greater ethical and experimental latitude possible with animal studies, as well as such practical considerations of expense and time advantages further argue for the utility of the preclinical approach. Such studies may substantially complement clinical efforts, and uniquely advance research in novel directions. Some reasons for considering preclinical models are included in Table 1 . It must, however, be recognized that models suffer several possible limitations. One immediate limitation of any actual model of psychopathology is the degree to which it indeed reflects a clinical disorder. If models are to be useful there must be pre-established means of evaluating the precise degree of commonality they possess in comparison with a clinical disorder. This is to say criteria of validity are necessary.

A number of approaches to systematic validity are possible. One approach relies upon face validity. When criteria are left unspecified, one or more common behavioral, motivational and pharmacological features have been taken as sufficient grounds for comparison and assessment. As noted, ambiguities of validating criteria may lead to confusion at many levels and more explicit criteria have been proposed by McKinney and Bunney [144], who include the following four considerations: the presence of similar inducing conditions, (i.e., a commonality of precipitants for animal and human disorders), behavioral and motivational similarity (i.e., phenomenological similarity), a common neurobiology, and similar responses to analogous therapeutic interventions. More recently Abramson and Seligman [1] have proposed related criteria, including procedural similarity with respect to cause, course, and response to intervention. They additionally note the importance of specification with respect to clinical subtypes, arguing that the variety of states of clinical depression precludes a general depression model. This last criterion is therefore an attempt to specify more precisely what is being modelled.

Criteria of the above types are necessary, and based upon both theoretical and less formal grounds, the specific criteria which have been proposed seem both reasonable and adequate. It should be kept in mind, however, that simultaneous realization of all criteria may be neither possible nor in fact necessary. In the first place, it may be necessary, particularly at early stages of model development, to use certain criteria to establish the grounds upon which other criteria may be evaluated. Only if a given model shares certain common traits with depression, it is worth looking further. Moreover, a high degree of uncertainty remains regarding the clinical neurobiology of depression, and comparisons are limited by this. Finally, for many purposes, it may be reasonable and heuristically valuable to isolate a more discrete neurobiological variable, for example motor retardation or diurnal variation, from a depressive syndrome, allowing more detailed and precise investigation. Models utilizing a more discrete dependent variable may not resemble human depressive disorders but may be valuable, nonetheless. The question of validity is relative and as will be seen, a model may be valid for certain but not for all purposes.

\section{PRECLINICAL MODELS AN INITIAL TAXONOMY}

Animal models of depression may be divided into two general categories which address rather different questions. On the one hand, many models have been developed for the
TABLE 1

THE UTILITY OF ANIMAL MODELS, IN THE STUDY OF DEPRESSION

1. Control of and manipulation of genetic history.

2. Short life span allows longitudinal study, within and across generations.

3. Direct experimental manipulations of and examination of brain possible.

4. Full control of life history.

5. Cost effective and time effectiveness.

purpose of identifying novel compounds of potential clinical use. These pharmacological tests, which vary in their empirical power are largely divorced from both clinical description and theoretical concerns; they make no necessary assumptions about the underlying mechanisms of depression, nor about the relationship of such mechanisms to the test procedures. While it is possible to present a theoretical rationale for their success it is not necessary to do so. Rather, they are used because of their empirical utility: they work (after a fashion).

On the other hand, a number of behaviorally and motivationally sophisticated models, based mostly upon some manipulation of social reinforcement or of environmental predictability, have been used for different purposes. This other class of model has been less concerned with drug screening and development and more concerned with the theoretical basis of depressed behavior. How does depression come about? What chemical, genetic, or environmental factors predispose towards or induce depressed states? What are the long-term consequences of early separation or disrupted environmental predictability? These models address the psychobiological substrates of the illness, making use of sophisticated observational and behavioral techniques.

Several points might be noted about these two types of model prior to a detailed discussion of either. First, the above categories are ideal types; few cases of either model exist in as pure a form as described. Many drug screens presuppose some theoretical rationale, and a few seem to combine equal amounts of theory and empirical applicability. Nonetheless, this distinction may be of taxonomic value. It is hard to imagine a reasonably accurate drug screening technique being discontinued because of a problem in theoretical rationale. Likewise, an interesting empirical approximation of depression in animals might be used quite successfully despite some inconsistencies with drug or neuroendocrine response. In particular it must be recognized that fundamental similarities across species do not rule out coexisting species-differences.

Finally, since the two classes of model have addressed separate issues it is unfair to expect any given model to embody the heterogeneous practical and theroetical concerns raised jointly by the two categories. While it would certainly be of value to design a model which is both practically useful and theoretically fertile (in fact that is the aim of the present series of papers) it may be unreasonable to expect present models to respond to questions which they were not originally designed to answer. Even within each category different models are motivationally and behaviorally diverse. Given these problems, cross-model comparisons may prove possible upon certain biological and behavioral dimensions; 
however, they may not necessarily be possible upon all of them at the present time.

\section{Empirical Models}

With these provisos in mind and looking first to those models which are used as empirical screens for antidepressant activity, we find three major classes of test procedure. These are: (1) antidepressant reversal of the effects of amine depletors, (2) antidepressant potentiation of noradrenaline or of sympathomimetically active drugs, (3) antidepressant modification of the muricidal response of rats. In addition to these major test types, a variety of other tests have occasionally been employed. These include modification of limbic seizure activity, and interactions with the hallucinogenic drug yohimbine.

The first of these techniques and perhaps the one which remains in widest general use involves the acute reversal of the effects of the rauwolfia alkaloid reserpine, or of its synthetic analog tetrabenazine. For example, antidepressants may reverse reserpine-induced ptosis in rats [54], salivation in dogs [219], hypothermia in mice [15,152] and hypoactivity in a variety of species $[30,206]$. Similar tests may be employed with synthetic reserpine analogs generally with consistent patterns of results $[174,230]$. Both classes of antidepressant agents, e.g., tricyclics and monoamine oxidase inhibitors, reverse reserpine's sedative and depressing effects but they must be given before the amine depletor is administered.

The reserpine model was developed soon after initial reports of drug-induced depression in humans who had been receiving the drug as an anti-hypertensive agent $[26,67,106$, $126,153]$ and it has been presumed that the reserpine model involves a direct assessment of clinically meaningful psychobiological components of the disease. It should be noted that more recent evaluations of reserpine effects indicate that the primary action of the drug in humans is upon psychomotor activity and not upon mood [26, 74]. In fact, recent reviews suggest that true depression may occur in as few as $6 \%$ of reserpine-treated patients $[74,148]$ and that these patients were likely to have had a prior history or family history of depression. On the other hand, very high doses of reserpine can produce severe depressive mood changes even in normal subjects [161]. Thus, the actual clinical incidence of reserpine-induced depression may reflect a biological predisposition to low doses.

Clearly since the reserpine model is intended as an empirical screening technique this problem may not of itself be particularly damaging. However, the test also embodies a number of practical problems. For example, the test predicts an ordering of antidepressant potency, e.g., that desipramine may be more powerful than other drugs such as amitriptyline, while the reverse may in fact be true clinically [25]. Even more problematic than this ordinal inaccuracy, however, is the large number of clinically noneffective compounds which reserpine tests suggest should be active, e.g., DOPA and alpha methyl DOPA $[38,51,58]$, amphetamines, antihistaminic agents, LSD and beta adrenergic blocking agents $[75,206,207]$. In summary, the reserpine test embodies both theoretical and practical problems, perhaps the most serious of which is the mis-identification of inactive drugs as potential therapeutic agents.

A second class of techniques makes use of noradrenergic (NA) potentiation of either a central or peripheral nature, or more generally of sympathomimetic synergism. Sigg [205] originally suggested a noradrenergic basis for the therapeutic mode of action of antidepressants, based upon the potentiation of the adrenergically mediated contractile response of the cat's nictitating membrane. While imipramine produced no direct effects upon the membrane it augmented to a considerable degree contractions induced by nerve stimulation or exogenous norepinephrine. Synergism of antidepressants with NA or NA-potentiating agents has been confirmed and expanded using a variety of pharmacological techniques. For example, DOPA, the precursor of noradrenaline produces hyperthermia and aggression, and imipramine can potentiate both of these effects $[61,62]$. Moreover, imipramine can potentiate amphetamine-induced changes in both physiology and behavior including amphetamine hyperthermia [152], amphetamine group toxic reactions [124], amphetamine facilitation of shock avoidance $[39,236]$, and amphetamine potentiation of brain stimulated behavior [216].

These synergism models have many of the same problems as the reserpine model. For example, they also fail to predict the ordinal relationship between clinical potency and test efficacy [208]. They also suggest an antidepressant potential for clinically ineffective drugs. This problem appears to pervade many of the proposed synergistic tests including the tests for activity, avoidance, and brain stimulation. For example, anticholinergics, antihistaminics, psychostimulants, and at least occasionally neuroleptic drugs interact with adrenergic mechanisms in a manner similar to antidepressants in all these tests $[27,40,124,207,214]$. A final problem with tests employing amphetamine potentiation is that imipramine slows the rate of metabolism of amphetamine and thus produces a pharmacokinetic rather than physiological interaction [123]. Additional discussion of the above varieties of test may be found in Rech and Moore [174].

The muricide test, in which the spontaneous attack patterns of a rat upon a mouse are reduced by antidepressants, also has many of these same problems. For example, just as above it fails to discriminate antidepressants from psychostimulants, antihistaminics and anticholinergics $[20,87,96$, 98]. A second murioid aggression test may also suffer from these same difficulties.

Cairncross and co-workers [37] have recently reviewed a series of studies on the olfactory bulbectomized rat. Bilateral bulbectomy produced an abnormal endocrine state resembling that of endogenous depressives, and tri- and tetracyclic compounds normalized both the irritability and abnormal endocrine state. From their reported findings, however, it appeared that monoamine oxidase inhibitors were not correctly identified by their procedure. On the other hand drugs of only equivocal antidepressant potential (e.g., experimental serotonin reuptake inhibitors) were found to be positive.

Other tests also embody these problems, either actually or potentially. Babington and Wedeking [17] used limbic seizure activity as a screen for antidepressant activity. Antidepressant drugs selectively depressed limbic seizure intensity while having only minor effects upon other, e.g., cortical seizures. Other drug classes like benzodiazepines or stimulants lacked this selective inhibitory action. Unfortunately, DOPA, anticholinergics, and antihistaminic agents were not tested. Likewise, Sangvhi et al. [191-193] have proposed a model of depression based upon the cardiovascular effects of the drug yohimbine in dogs. Antidepressants selectively potentiated these cardiovascular effects, but no information is available regarding anticholinergic and antihistaminic drugs. Another behavioral model of potential interest is the 
chronically isolated rat [70]. Garzon and co-workers have suggested that only clinically effective antidepressants selectively inhibit isolation induced motor hyperactivity. This model may bear some conceptual reflection both to the irritability model of Cairncross and to theoretical models involving social deprivation. All of these last tests still require more extensive testing and none has yet seen general acceptance, although they may eventually gain wider use. A successful test should be able to discriminate anticholinergic drugs, antihistaminic drugs, amphetamine, DOPA and alpha methyl DOPA from truly effective antidepressants.

It is clear that many of these tests actually or potentially suffer from problems of specificity and selectivity. They may miss certain clinically effective drugs while at the same time they frequently suggest that ineffective drugs will be of therapeutic benefit. Yet other tests require empirical evaluation.

Unfortunately many tests by their nature embody an inherent circularity. Tests begin with known antidepressants and tend to be successful in identifying related members of the same pharmacological class. The tests become progressively less useful as they move from congeners to novel drug classes. Yet, it is precisely for the identification of novel drugs that screening techniques are most necessary.

What is clearly needed is a test or series of tests which: (a) may be theoretically grounded, i.e., test antidepressants by directly addressing a presumed pathogenic mechanism; and (b) are sufficiently flexible at a pharmacological level to allow extensive testing and accurate screening for novel compounds. Moreover, such tests should be (c) selective and accurate in their identification of new compounds.

\section{Theoretical Models}

The second category of models is more theoretically and generally more behaviorally oriented. The two major depression-producing manipulations which have been employed each presuppose a related human life experience which contributes to the clinical disorder. The first of these is the separation model, and the second involves learned helplessness. A third group of models, upon which relatively less research has appeared, involves biological rhythms.

\section{SOCIAL ATTACHMENT MODELS OF DEPRESSION}

\section{Description}

Disruption of mother-infant bonding or of peer bonding in young animals produces a series of affective changes resembling depression. These changes follow a uniform course. Initially an infant will display protest behaviors including vocalization and motor agitation. Depending upon species, strain, and prior history of socialization, this subsequently yields to varying degrees of behavioral despair, characterized by retardation, loss of primary drives, resignation, and refractory loss of interest in normal surroundings. While the despair response is present in most species, its intensity and duration may vary considerably. Finally, this second stage may develop into a stage of indifference in which social reunion provokes comparatively little interaction. While the primary state of agitation is universal, the second stage is present but somewhat more variable in magnitude. The third stage is rarer in occurrence both within and across species, and may in fact be absent from the repertoires of many animals. The presence of indifference and relatively more pronounced despair reactions may, to some degree, be limited to altricial species (i.e., species not fully mature at birth, and requiring more extended maternal care).

\section{Comparative Aspects}

The protest stage of separation appears to be a prevalent psychobiological response. King [113] and Hoffman and Rattner [95] argue convincingly that the essential phenomena found in mammalian attachment behavior are present in the normal course of imprinting in precocial birds. Shapiro and Garretson [203] have also argued for a common basis for avian and mammalian social ontogeny. While agitation and distress calling to separation are reliable responses, no evidence has been presented suggesting that the syndrome is further differentiated to states of despair or indifference.

Protest has also been noted for rodents. (Labarba, White and co-workers [121-123]). Peer-isolated mice may also be behaviorally depressed as adults [121], in addition there may be an overall change in physiological status such that they are more susceptible to disease than grouped mice. On the one hand earlier reports from the same group noted increased resistance to disease after early maternal separation [121-123]. This finding in itself is surprising, and may represent a species or strain peculiarity. The reason for discrepant findings may rest with procedural alterations across tests, including alterations in age at separation and initial housing density.

Hofer and colleagues have shown a variety of typical separation induced effects in the immature rat. In their design acute maternal separation produced an initial protest response which included behavioral changes of motor hyperactivity, self directed grooming, defecation and urination $[91,92]$. These alterations have been shown by others to be accompanied by high frequency distress calls $[154,155]$. In addition to the above behavioral changes, physiological changes including sleep disturbance and bradycardia [92] were also found to be present. While the sleep disturbance was reduced by supplementary feeding [92], other prominent cardiac effects, behavioral and physiological alterations (e.g.. susceptibility to gastric erosion. increased activity) were not significantly altered. Only the presence of odor or tactile cues from the mother or another conspecific reversed the remaining aspects of protest $[3,163,164]$.

It should also be noted that maternal separation significantly increased the morbidity risk of young pups [163] with $80 \%$ or more dying within a few days of separation. This suggests a despair-like stage is also present in the rat. Again, presence of conspecific cues significantly reduced morbidity [192]. Even in reunited pups, however, maternal separation induced long term physiological changes, such as increased susceptibility to stress induced gastric ulceration in adulthood [3]

In addition to the above behavioral changes a specific decrease in serum growth hormone has been reported to accompany separation in young rats. This may be regarded as a physiologically distinctive stress response since remarkable changes in prolactin, corticosterone or thyrotropin were not present upon assay $[63,120]$. Evidence has also been presented indicating this response to be mediated by tactile stimulation [63].

At least one lagomorph (the guinea pig) also shows separation induced protest $[85,114,170,228]$. In contrast to the above reports on altricial mice and rats, however, acute post-separation motor agitation was not seen. Separated 
guinea pigs displayed distress calling and relative motor retardation $[85,170]$. Two explanations have been advanced for the motor effect, these being conspecific facilitation of exploration (i.e., a loss of normal exploratory behavior during separation) and directed but environmentally localized agitation and attempts at reunion if maternal cues are present but inaccessible. Herman and Panksepp [85] reported that guinea pigs remained in the immediate area of separation but vigorously attempted to reunite themselves with their tactually inaccessible mothers during experimental testing. This lends credence to the second explanation. In this same report, they also noted pharmacological reductions of distress calling and provocations of distress by opiate stimulation and blockade, respectively. The presence of opiates in social reinforcement has also been suggested for other species (e.g., birds [160] and dogs [159]).

Many of Panksepp's studies suggesting a role for endorphins in social behavior use a social contact measure following injection of opiate or antagonists. It must be appreciated that such measures are not without their problems, especially in opiate research. On the one hand many agonists can produce a core hypothermia, in which case increased proximity may represent an attempt to adapt to a thermal stress: on the other hand antagonists may increase the intensity of a variety of noxious stimuli, and intensify the negative aspects of a motivationally mixed social-stimulus.

Rather limited data on cats indicate significant separation induced distress calling but few prominent motor alterations $[178,182]$. Social rather than environmental cues have been shown to control the increase in distress calling, since maternal contact in a novel environment is sufficient to alleviate otherwise present vocalization.

Dogs and monkeys both typically are extremely social species, and are the two most extensively studied-non human animals. Scott and colleagues have investigated the effects of social manipulation and social deprivation upon young and mature dogs for some two decades. It is evident that major strain differences occur in separation induced vocalization and motor agitation in dogs, even if only brief (approx. 10 minutes) separation periods are employed. Ontogenetic effects are also well documented, as are strain differences in deprivation induced disorders of socialization and behavior (the isolation syndrome and its milder version, the kennel syndrome, $[195,196])$.

Dogs form strong social bonds both to other dogs and humans. Prolonged isolation of well socialized dogs precipitated both acute distress and agitation, and subsequent retardation, weight loss, and death [196]. Senay [201] reported profound separation induced retardation in six well socialized adult German shepherds and Scott has reported similar findings for a Shetland sheepdog [196].

Limited work has directly addressed the biological concomitants of distress reactions in acutely or chronically isolated dogs. The acute distress and activation response involved cardiovascular concomitants including a labile tachycardia which was reduced or reversed to bradycardia by petting. Changes in systolic blood pressure also followed this pattern [136].

Earlier drug studies suggested imipramine was selectively active in reducing vocalization in beagles, beagle hybrids, telomians, and terrier-sheltie hybrids. On the other hand, major and minor tranquilizers and psychostimulants were ineffective in altering distress, except possibly at debilitating dosages [195]. It is in fact rather surprising that amphetamines did not affect the acute distress response since psychostimulants have been reported to be quite effective in treating acute loss reactions and demoralization in humans [116]. The existence of species differences in amphetamine response cannot be dismissed, and further studies in animals would be helpful in allowing a more detailed comparison. Furthermore, while imipramine was tested as an acute 8 $\mathrm{mg} / \mathrm{kg}$ dose its therapeutic effects are in fact cumulative, and generally not clinically evident for a 2-3 week period [156]. Given the above, the possible contribution of imipramine's prominent anticholinergic (dry-mouth) properties cannot be excluded entirely. Chronic studies of antidepressant treatments are of critical importance for the further evaluation of the canine model.

The plasticity, breadth, and complexity of primate behavior, and the evolutionary proximity of humans and nonhuman primates render observations upon this order of particular interest. Dramatic separation induced protest reactions (vocalization, crying, motor agitation, finger sucking. oral stereotypy, insomnia of up to six days in length) were reported by Bakwin [18], Spitz [213] and Bowlby [31] in a population of 6 month to 6 year old institutionalized children. In approximately $20 \%$ of the observed cases continued separation produced an anaclitic, or dependency depression. with prominent psychomotor retardation, stupor, disinterest in surroundings, reduction in normal physical growth, and a significant stress morbidity risk. Upon reunion, most children resumed normal activity and social interaction, although a small percentage showed psychological detachment and withdrawal. Human anaclitic depression may at least upon behavioral grounds resemble both agitated (during protest) and retarded (during despair) depression in adults. Whether anaclitic depression is actually a subtype of adult depression is still unclear, and this will be addressed below.

Turning to non-human primates, it is evident that the biphasic response to separation is present and well defined, particularly in old-world monkeys, although species differences may influence its duration and intensity. In most cases (i.e., for macaca mulatta, m. nemestrina, m. iris.) protest reactions consisting of screeching, cooing, motor agitation. sleep disturbance, and appetite disturbance occurred within the first 24-36 hours of maternal separation. Within the next $48 \mathrm{hr}$ this evolved to a state of withdrawn despair. Infants appeared severely retarded in motor activity and typically remained huddled, with lower vocalization and a typical absence of social engagement (i.e., play behavior). Recovery occurred within the next 2-4 weeks of separation, although recurrent episodes of despair were intermittently present. In its most extreme form (i.e., following the actual death of an adult) the distress reaction led to a failure to thrive, and death within a few months $[60,78,79,81]$.

A variety of factors may influence both the degree of initial distress and the presence and course of subsequent despair. In a series of extremely thorough studies by Kaufman, Rosenblum, and co-workers, the separation reactions to maternal removal in group living macaca nemestrina (pigtail macaque) was compared with that of macaca radiata (bonnet macaque). These studies $[110,111]$ indicated early non-maternal social exposure in bonnet macaques, particularly ventral contact and group huddling, reduced the intensity of separation distress and typical despair. The authors attribute these differences to group living situations. Pigtails have close consistent maternal contact but limited nonmaternal contact. The family group is typically isolated and nuclear. On the other hand bonnets tend to huddle, and bonnet infants receive greater non-maternal contact. For bonnet 
macaques, maternal absence typically provokes successful adoption by another adult; in the case of pigtails, however, adults may actually harass separated infants.

Kaufman and Rosenblum consider the biphasic response upon a continuum of successful adaptations. Both active and passive aspects of the response are similar to the response patterns described by Engel [59] involving anxious seeking and conservation-withdrawal.

Similar findings upon social factors and social differences have been noted by other researchers in a new world species (Patas monkeys: (erythrocebus patas) which typically are closer to bonnets than pigtails in terms of their behavioral responses [172]). Similarly squirrel monkeys (saimiri scivreus) show agitation but relatively short-lived despair [107]. These findings suggest early rearing and social support may be important determinants of the degree of depressive behavior in primates. These factors also may explain some of the variability associated with responses of human infants (see below).

Findings of cross-species effects must be further tempered by the realization that a good deal of individual variability exists in the expression of affect even within species. Species effects may be modified by other factors. For example, pigtail macaques from alpha (dominant) females are less prone to despair than their peers [111]. Also at least some bonnets may show despair if supplementary support is limited [112]. Other reports of extreme behavioral variability using a large sample of rhesus monkeys and a series of replications have been presented by Lewis et al. [134]. In counterdistinction to earlier reports from this and other groups, they noted neither consistent agitation nor consistent despair responses. Since this study employed a sample size larger than any other study it will be discussed further below.

The influences of variability and social factors fit well with observations on non institutionalized human infants. Robertson and Robertson [181] report a reduction of most separation induced depressive behaviors, and complete adjustment to foster care, given a normal history of antecedent family interaction. This suggests that anaclitic depression may be a highly atypical response. It should be recalled that initial reports suggested a rather low incidence $(\sim 20 \%)$ for the syndrome, even in as unsupportive an environment as that represented by institutional facilities.

\section{Additional Factors}

Other factors which have been identified in the control of the biphasic affective response in primates include age. A particularly severe affective response is common at approximately 90 days. This may reflect an interaction of separation and increased fear $[189,211,212,224]$. Other ages under a year appear equivalent in their effect.

In addition, behavioral responses may be a function of separation length, with longer separations producing more severe depressions $[211,212,220]$. Other factors, including social setting, history of separation, maternal influences, and sex differences are reviewed by Hinde [88] and Suomi and Harlow [225].

Peer separation in which group reared monkeys are subjected to some of the same manipulations as mother-infant pairs has been used to extend previous studies. This approach may reflect the social disorganization and affective responses which are more typically seen following divorce or bereavement in humans. In younger (less than 1 year) monkeys the response to separation is relatively more intense and again is characterized by the biphasic course seen after maternal separation [220-226]. Extreme vulnerability to social separation may be present for at least the initial five years of life [143]. Virtually all predisposing factors which modify maternal separation act in an equivalent manner for social separation $[220,225]$. In addition peer separation may permanently retard normal social development. Suomi [220] has suggested that a number of factors determine the course of depression after peer separation. These include loss of a significant social stimulus; absence of replacement stimuli: and absence of adequate means of altering the newly reduced social environment. Other techniques which have been used to produce grossly aberrant behavior include extreme sensory isolation in a tunnel $[223,225]$. These studies may bear some relation to depression and are reviewed in Suomi and Harlow [225]. This model may also bear some resemblance to helplessness, or to pathological social hyperreactivity as seen in other species [70,229], and may have long term consequences on social behavior [243].

The response to separation has also been studied from a physiological point of view and changes occurring during separation may bear some resemblance to the disordered physiology of human affective disorders. Reite et al. [176] and Reite [175] report initial tachycardia, elevated temperature, and a sleep disturbance with fragmented and reduced rapid eye movement sleep in acute primate protest. Such patterns are more typical of insomnia in humans, rather than depression, although it might be recalled that separation may itself elicit insomnia. As protest yields to despair, a relative bradycardia and hypothermia are present. Unfortunately, further analyses of REM sleep patterns are not available. Such longitudinal studies would be useful in allowing a more adequate evaluation of possible physiological similarities to clinical disorders especially given the clinical studies of Kupfer and colleagues [119]. If primate separation induced depression is in fact a variety of endogenomorphic depression [115] then absolute values for REM latency would be expected to decrease to below normal levels while REM density increased. Separation also produces markedly elevated cortisol values in infant squirrel monkeys and rhesus macaques $[48,86,210]$ which is similar to endocrine responses in severe clinical depressions [42-45]. Some differences have emerged with respect to maternal cortisol response, although it is elevated at least in squirrel monkeys [48]. Hill et al. [86] have suggested the presence of a social surrogate may lower this response in rhesus monkeys although this again may be species specific $[48,84]$.

A related approach which has taken a stress-diasthesis model as its basis also has pointed to possible physiological variables of interest. Kramer and McKinney administered relatively low doses $(\sim 25 \mathrm{mg} / \mathrm{kg} / \mathrm{day})$ of the tyrosine hydroxylase inhibitor $\alpha$-methylparatyrosine to rhesus monkeys. This dose was behaviorally inert in normal social settings involving mothers or peers (see below), however, when chronically drug treated monkeys were peer-separated, the normal depression response was significantly intensified. Based upon a review of previous data the authors suggested the drug was more effective in augmenting depression in the peer separation model than it was in the maternal model. A direct assessment of the maternal model was not included in their report however. Neither PCPA, a serotonin biosynthesis inhibitor, nor fusaric acid, a norepinephrine biosynthesis inhibitor, were equally effective in altering behaviors after separation. On the contrary fusaric acid may have been somewhat activating in their model, effectively ruling out any exclusive noradrenergic contribution. Based upon con- 
comitant activity measures the AMPT effect appeared mood specific in nature. These findings point to the involvement of one or more catecholamines in the behavioral disturbances accompanying primate depression.

\section{Therapeutic Intervention}

One finding of interest using the peer separation model concerns "behavioral therapy" by conspecific peers. The presence of such a conspecific "therapist" may reduce or eliminate typical depression. Positive changes in play, sexual behavior, general activity, and reduced self-directed behavior were observed by Suomi et al. [222]. Given the limited activity of behavior therapy for endogenous depression this would imply a possible relation to grief responses and neurosis. It appears, however, that drugs too are of value in the syndrome.

In one recent epxeriment using the peer separation model, Suomi et al. [226] found that separation-induced distress, self clasping, and huddling were reduced while exploration and activity were conversely increased by drug treatment with the tricyclic antidepressant imipramine. This ef fect was apparent only with chronic drug administration. Similar findings were recently reported by a second group of researchers using a double blind design [101]. The efficacy of antidepressant treatment in primate separation is further suggested by the earlier investigation of Kraemer et al. [118] upon the antituberculosis agent isoniazid. Isoniazid is also a weak inhibitor of monoamine oxidase which may nonetheless have a chronic cumulative effect and therefore serve as a potential antidepressant. It is routinely included in the diets of the Wisconsin group and some other primate laboratories as a prophylactic procedure. It was noted in the investigation of Kramer et al. [118] that grouped animals showed higher baselines of social interaction with isoniazid present, and separation induced and pharmacologically induced depressive symptoms were more severe when the drug was absent. This of course calls the validity of studies in which the drug was routinely administered into question. It has already been noted that Lewis et al. [134] could not confirm many of the basic findings of separation induced affective changes. It has been argued that the inconsistency of findings is a reflection of individual differences in vulnerability which may also occur in humans [143]. The failure of Lewis et al. [134] to find a clear depressive response might also possibly be viewed in terms of the routine presence of this drug. This may be interpreted as a further confirmation of the efficacy of pharmacotherapy, or as a post hoc explanation of negative findings. The depression brought about by chamber separation may be responsive to electrocortical shock [133] but ECT treatment is only partially effective in restoring normal social reactions.

Procedural difficulties make any summary statements upon the relationship of separation and depression difficult. It may be speculated that initial distress is related to the agitation sometimes seen in unipolar depressions. This must presently be left as speculation, however, and it should be recalled that agitation is absent from many depressions. Whether the profound refractory loss of interest seen in despair reactions is a form of retarded depression also remains an open question. As noted, anaclitic depression may be absent in normal early separations in humans [181], suggesting the importance of a prior history of abnormal rearing in the elicitation of this particular response. Rie also [179] has raised a number of theoretical objections regarding the exist- ence of depression in childhood and its use as a model state for adult depressive disorders. It seems clear then that a number of theoretical and empirical differences may exist between these states. If anaclitic depression is a rare pathological response unrelated to adult depression then crossspecies comparisons are of only limited use. The utility of the model then must be evaluated with caution pending an adequate identification of the degree and type of overlap between depressive types (i.e.. child vs adult) within species.

\section{Learned Helplessness}

Seligman and co-workers have suggested the term "learned helplessness" be applied to the acquisition and performance deficits seen in avoidance learning and related learning tasks following pretreatment with inescapable aperiodic shock (preshock). Helplessness is conceived as a cognitive deficit due to a previous history of ineffective coping. The helpless animal enters a learning situation with a generalized associative set that its actions are without consequence. It therefore responds less, or not at all [140,198]. In addition to an acquisition deficit, other features of the helpless animal parallel clinical dimensions of depression. Changes in activity, food intake, and weight have all been reported [231].

The term "learned helplessness" is a relatively new one, and its current conceptualization represents the efforts of a small group of co-workers. Nonetheless, the theory does have a number of antecedents within the clinical literature. Goldstein [73] has elaborated a theory in which environmental mastery through behavioral means is necessary for mental health. Rotter's $[184,185]$ conceptualization of internal control suggests that belief in one's personal efficacy in a given circumstance will determine coping and behavioral patterns.

Although less immediately related to cognitive concerns, an emphasis upon antecedent stress and both physiological and psychological coping can also be found in the psychosomatic literature. Engel's conception of a continuum of active and passive coping has already been noted. Other examples which illustrate a similar concern may be found in Greene [76.77] and in studies of urban stress [71]. Such antecedents of course do not detract from the importance of helplessness as a unified and unifying theory of behavioral adaptation.

The phenomenon has been reported in a variety of species and testing situations. Typically a biphasic response to training has been observed. Shock initially produces agitation, struggling, vocalization, and unsuccessful attempts at escape. Continued preshock produces apathy, withdrawal, and eventually an associative failure in novel circumstances. Typically, failure to learn is considered the basis of the behavioral deficits.

\section{SUBTYPES OF MODEL}

Two distinctive variants of helplessness models have now evolved. Animal models continue to rely upon the initial formulation as stated above, while clinical analogs and explanations have been revised based upon experimental findings. Depue and Monroe [53] have noted a number of practical and theoretical concerns in the direct application of the preclinical model to a clinical setting. These include potential nosological confusion and possible qualitative differences 
between subclinically depressed college students and more seriously depressed psychiatric populations. These concerns are supported by fundamental inconsistencies and ambiguities in the major clinical support for helplessness [49] by failures to find evidence of helplessness [237], and by findings of cognitive distortions which more closely resemble Beck's [22] model of overinclusive self blame and internalization rather than cognitive helplessness and causal irrelevance.

Given these problems Abramson et al. [2] have suggested that human helplessness should be reconceptualized as an attributional process with attributions occurring within three dimensions. These dimensions include internal vs external control, stable vs unstable character of aversive stimulation (alternately this may be seen as a dimension including transience vs persistence) and specific vs global nature of response (this is a novel dimension in attribution theory which is intended to characterize the relation of coping to a possible range of behaviors, global factors being those which effect a number of behaviors). In the revised model, for example, helplessness might be predicted if a cause were internal, stable, and global (i.e., it's my fault, the problem is there in all circumstances, and I fail at everything), but not if a cause were external, unstable, and specific. The reader is referred to Abramson et al. [2] for a further discussion, to Wortman and Dintzer [242] and Heusmann [100] for critiques of the systematic adequacy of the reformulation, and to Garber and Hollon [69] for an empirical investigation of the model in a student population. In this last study the dimension of universality did not contribute to helplessness as would be predicted. At this point at least some doubts persist regarding helplessness as a significant causative factor in depression [35]; nonetheless, helplessness in animals may represent a simplified version of at least some of the clinical phenomena of depression. Given evidence of a persistent behavioral deficit in animals, major preclinical studies will be reviewed below.

\section{Species Generality}

At a species level helplessness has been reported in fish avoidance conditioning $[23,158]$ although recent reports by Bitterman and colleagues [241] suggest that the avoidance response in fish is a respondent rather than instrumental response. This may in turn suggest that helplessness in teleosts is not analogous to mammalian learned helplessness, but perhaps a form of habituation. Informal observations of fish in discrete avoidance (Katz, 1974, unpublished) suggest that preshock may facilitate rather than hinder one-way active avoidance. This finding may reflect sensitization within the respondent conditioning situation, and is consistent with a respondent interpretation.

Helplessness has been reported in mice [33] and occasionally also in rats. Recent reports include Looney and Cohen [135], Maier et al. [139], Katzev and Miller [109], Seligman and Beagley [198], Shurman and Katzev [204]. Recently Hatotani [82] has independently evolved and proposed a depression model which possess a number of similarities to helplessness. The inescapable stimulation of this last model has involved extensive forced wheel running activity and has been correlated with both behavioral and endocrine abnormalities.

Not all reports of helplessness in rodents have been positive. Freda and Kline [66] and Beatty [21] could not obtain the helplessness effect. Other studies have reported helplessness only under highly specific and restricted parameters of response difficulty. Exceeding these parameters with either too easy or too difficult a task requirement disrupted helplessness. This last finding both effectively eliminated response effort as a comprehensive explanation of non response and suggested that the response deficits in rats may be rather transient. Anderson and coworkers $[7,8]$ have argued that helplessness is only seen if immobility is present during shock. A related interpretation of Wilson [238] argues that the aversiveness of back shock (the most widely used method of delivery by the Pennsylvania group) may be attenuated by postural manipualtions which might subsequently affect new (escape) learning. Further studies of the role of immobility are presented below.

The studies of Amsel [44] have noted a yet more radical exception to learned helplessness. In their studies of preshock and runway performance, helplessness training in fact facilitated initial acquisition and retarded subsequent extinction in an appetitive task. This may be interpreted as a potential increase in "persistence". A similar finding in humans has been noted by Roth and Kubel [183]. At the very least it must be argued that restricted phylogenetic, conceptual, and procedural boundaries exist for the helplessness phenomenon. Some investigators have obtained the effect but only in conjunction with debilitation and gross motor ataxia. Weiss and colleagues $[28,72,233,234]$ initially suggested the interference effect seen with acute cold swim stress or inescapable shock is a nonassociative performance deficit, although more recently they have argued that some persistent learned effects may occur as suggested above (by Wilson) or possibly as learned incompatible motor responses [9,72]. Motor competition or neurochemical depletion as opposed to cognitive deficits have also been proposed by a number of other investigators including Anisman and Waller [13]. Bracewell and Black [32], Burdette et al. [36], and Levis [131]. Recently neurochemical deficits, particularly related to noradrenaline have been identified [11]. Also. Jackson et al. [104] have elaborated a multiply determined model involving both psychomotor inhibition and a more persistent associative deficit. At least one neurochemical factor contributing to the more acute immobility response may be opioid [141] and by this interpreiation immobility might reflect endogenous antinociception.

Two experiments from Maier's laboratory strongly support a cognitive contribution to helplessness induced performance deficits [137]. When the avoidance contingency involved immobility (DRO; differential reinforcement of other behavior) rather than active avoidance, experimental dogs subsequently acquired an active response, while yoked dogs did not. The DRO group was slightly retarded in comparison with naive subjects, however it was superior to yoked animals, which frequently failed to acquire the response. Clearly immobility was not a sufficient cause for helplessness since an immobile group was superior to a more active yoked group.

In a second experiment [105] rats were exposed to a helplessness procedure and later tested on a discriminated passive avoidance procedure. Rats were retarded in the acquisition of this response due to a failure to inhibit inappropriate responding. Since a second group of matched subjects was tested for a classically conditioned suppression, and since no difference was found between yoked and helpless animals, it appears that (1) some long term response deficit related to response-outcome learning, but not to stimulusresponse learning was present and (2) motor inhibition can- 
not account for all aspects of the long term interference effect. Maier and co-workers [139] also have argued that based upon specific disruptions of choice accuracy it is possible to dissociate cognitive from motor processes in helplessness and in a very thorough series of experiments they showed specific disruptions of choice learning in a Y-maze. Although they present a compelling case, another recent and procedurally related study by Anisman et al. argues against a cognitive deficit in T-maze discrimination in the mouse. Although failure to respond was obtained this appeared to be dissociable from a constant high discrimination accuracy [102]. The issue therefore remains unresolved.

It might be noted that studies on cats $[202,227]$ and dogs $[157,199]$ have incontrovertibly demonstrated profound learning deficits. Deficits of a highly circumscribed nature have also been reported for humans after noise stress $[89,91]$ and after shock [173]. This therefore may not be a generalized effect. The ubiquity of a behavioral disturbance in dogs and cats and relatively mild deficits seen in human experiments also might point to differences based upon procedural or phenomenological grounds.

\section{Theoretical Generality}

Helplessness rests upon a premise that reduced environmental contingency produces a specific cognitive response. However, other theoretical approaches have stressed the associative neutrality of random stimulus presentations. Indeed considerable evidence supports the random procedure as a neutral control for associative operations. If random pairings produce no net associative effects it is not clear they can serve as a basis for yet more complex cognitive adjustments which are the basis of helplessness theory.

Associative neutrality and complex cognitive function cannot readily coexist. At least some of the deficits of helplessness in fact appear to be cognitive in nature. Thus, some resolution of apparently contradictory theoretical and empirical data is necessary. Two points of resolution are possible. In the first place it is clear that associative neutrality is not a necessary outcome of all random procedures. Examination of the initial models supporting the neutral position indicates a number of potential exceptions. Factors influencing the degree of associative strength consequent to random pairing operations include reinforcement density, number of initial random pairings and conditioning time course. Both computer stimulations and empirical studies suggest such factors may play rather important roles. Nonetheless, the existence of associative strength may be necessary but not sufficient for the cognitive process underlying helplessness. The initial associative strength results from positive pairing and therefore represents a causal (predictive) relationship.

A second potential point of integration concerns the extended time course necessary for the cognitively based helplessness effect. Associative neutrality may be assumed to occur in an intermediate time span. The initial conditioning phase is positive, and only subsequently becomes neutral. It is possible that a third phase emerges over time, given continued "hypothesis testing" by the subject. This is a potential point of integration, but it has not been tested empirically. Such a test is theoretically important in resolving these issues.

McReynolds $[146,147]$ has offered a yet more radical theoretical challenge to helplessness, and has suggested a reformulation of major findings in terms of schedule shift effects, particularly effects analogous to those found in extinction following partial reinforcement, in which discrimination of altered circumstances may facilitate nonresponding. This reformulation again clearly detracts from any simple or direct relationships to clinical depression.

Critiques of the McReynolds' position have also recently appeared $[132,138]$ but it should be emphasized that the major points raised, i.e., those concerning the critical nature of situational discriminability in reducing response rates, must be considered.

\section{Therapeutic Intervention}

A number of experiments have attempted to reverse or prevent helplessness. Given the claim that helplessness is closer in resemblance to neurosis [150], it is surprising but nonetheless of interest the electrocortical shock (ECT), an intervention more common for psychosis, is nonetheless therapeutically effective in restoring behavior in dogs [55]. Similar findings have been reported for the rat; however the time course of the effect may indicate a primary effect upon memory consolidation [34]. Tricyclic antidepressant drugs may also be of therapeutic benefit [162]. Antidepressant reversal of helplessness using a MAO inhibitor was reported by Weiss et al. [234].

Porsolt and colleagues have recently developed a related model of "behavioral despair" in rats and mice [166-169] which utilizes swimming in a confined space to induce a state of immobility. Several features of interest of this model include a genetic predisposition involving high or low vulnerability to despair and drug treatment [168] and the selective reversal of despair by ECT and antidepressant drugs. This test then combines genetic and environmental determinants, a theoretical rationale, and an efficient drug screening technique. Some question has recently arisen regarding the selectivity of the procedure and recent reports indicate that many clinically ineffective drugs, including reuptake inhibitors of NE and 5HT, DA stimulants, 5HT receptor agonists, Yohimbine, and PCPA were positive in this test. This may severely limit its empirical utility. In addition the time course of drug response is somewhat surprising in that acute treatments, which generally are ineffective or in fact initially depressant relative to placebo in humans are nonetheless useful in reversing the despair response.

Other less orthodox treatments which have been used in the treatment of helplessness include injection of antiserum to vasopressin, a peptide believed to be involved in memory formation and retrieval [128]. The finding of disrupted helplessness in antiserum treated rats strongly supports a learned component. Pharmacological manipulations have also included a number of manipulations of central aminergic systems. Injection of the serotonin biosynthesis inhibitor p-chlorophenylalanine (PCPA) did not reverse helplessness [6] suggesting serotonin is not directly involved in the syndrome. On the other hand, drugs as diverse as L-DOPA, a catecholamine precursor, scopolamine, an anticholinergic drug, apomorphine, and clonidine were effective in restoring normal activity and avoidance [12]. It must be stressed that none of these treatments is particularly useful in clinical treatment. Some of these drugs, primarily clonidine, may precipitate depressions. This casts doubt upon the similarity of helplessness and clinical depression, and would be more consonant with disrupted psychomotor function. 
Behavioral therapy involving forced responding has proven to be of particular utility in reversing helplessness in dogs and rats $[199,200]$. In addition, pretreatment with escapable tasks may "immunize" animals so they do not subsequently show a behavioral or motivational deficit [197. 199, 200].

Few studies have attempted to investigate psychoendocrine correlates of the syndrome. However, if Hatotani's [82] model is assumed to represent an acceptable variant of helplessness, then it is clear that major disruptions are present at least within the hypothalamic pituitary gonadal axis. These changes are also accompanied by altered disposition of central norepinephrine and dopamine. Weiss and colleagues have further reported lowered norepinephrine as a possible contributor to the phenomenology of helplessness $[234,235]$. These studies are supported by Anisman et al. [10, $11,12]$ who demonstrated that virtually all effects associated with helplessness may be achieved through reductions in central catecholaminergic activity or increases in central cholinergic activity. Such findings are attractive given noradrenergic theories of depression [194]. On the other hand, such theories are not without their own problems [148].

\section{Additional Neuroendocrine Studies}

One particularly useful but relatively underutilized biological dimension for the study of cross-species similarities is through direct neuroendocrine analysis. Hatotani's depression model offers one potential means of producing an endocrine state possibly related to some of the major clinical dimensions of depression. Endocrine concomitants of separation, particularly growth hormone and adrenal hormone elevations, have also been noted. Similar findings may occur in other procedures as well [165]. Insofar as specific neurochemical-neuroendocrine relations are established, e.g., between dopamine and prolactin, serotonin, acetylcholine, and cortisol, or biogenic amines and thyroid hormone, it is possible to examine central nervous system influences both clinically and preclinically using a peripheral measure [65]. Thyroid status may prove potentially important (e.g. $[68,82])$. To date, and largely because dopamine may be more directly related to schizophrenia than it is to depression, the prolactin response has been little utilized in animals. The recent report of Extein and colleagues demonstrating a reduced prolactin response to opiate stimulation in depressives may point to a potentially useful preclinical measure. It must be emphasized that neuroendocrine measures need not be viewed as exclusive measures, but rather as useful adjuncts to behavioral and biochemical measures offering a further means of both approaching a given model's systematic validity and indirectly probing central nervous system neurochemical status through observation of peripheral endocrine output ([65]; for further examples, see [82]).

\section{MODELS UTILIZING BIOLOGICAL RHYTHM DISTURBANCES}

The presence of biological rhythm disruptions in depression has long been recognized. One hypothesis of depression rests with an underlying rhythm disturbance $[232,239]$. A third class of models of potential clinical significant might, therefore, involve disruptions of normal rhythms.

Baltzer and Weiskrantz [19] have hypothesized that the cause of depression is related to a lack of synchrony in diurnal physiological rhythms. In their model, antidepressants would achieve their effectiveness through a re-synchronizing ability. The authors have presented a model of depression based upon the adjustment of activity patterns to phase shifts in daily light-dark cycles and have found imipramine selectively facilitates adjustment to phase shifts. Since diurnal activity is disrupted in depression [119] this model may be a means of approaching these disturbed patterns. It may be of interest in this regard that phase advancement of the circadian sleep-wake cycle has been proposed as an antidepressant treatment at a clinical level $[232,239]$.

We have noted that normal exploratory behaviors in extended sessions bear a number of similarities to mania and depression. Rats put in a novel environment show initial hyperactivity for 60-90 minutes, followed by a period of quiescence. If observations are continued, rest and exploration alternate in a regular fashion. The episodes of exploration have quantifiable amplitudes, period, and cyclicity. These may be modified by lithium in a manner analogous to manic-depressive disorders. Lithium lowers both the amplitude and frequency of exploration related activity [108]. This may be a useful and clinically relevant model of a drug sensitive recurrent process. Other models have also noted the utility of cyclic events in modelling depression [117].

\section{A Synthesis}

The multiplicity of approaches and models makes comprehensive statements difficult. Moreover, if models are successful, this difficulty is further compounded by validity of specific subtypes of depression with clinically complex primary phenomena. A number of points might nonetheless be usefully extracted from the majority of the reported studies. Examination of the two major classes of theoretical model indicates a universal procedural dependence upon stress. Separation entails socially mediated distress. Helplessness involves actual trauma. Models utilizing photoperiod shifts also involve a necessary activation of and adjustment of pituitary adrenal mechanisms. As Anisman $e t$ $a l .[10]$ and Porsolt [168] note, the universal requirement of stress may be modified by a genetic predisposition. One potentially useful elaboration in future depression studies may involve breeding experiments. Such an approach combined with concomitant investigation of central and endocrine fac. tors would allow a further specification of brain mechanisms invoked in both vulnerability and behavioral depression.

It is easily overlooked but (a) many of the same species show both helplessness and separation induced depression. and (b) both models embody a biphasic behavioral response. In both helplessness and separation models an initial agitated attempt to escape aversive circumstances is replaced by retardation and an overall lowering of emotional tone. Given both species and procedural commonalities, it may be speculated that both models share a common basis. The model of Engel [59] as elaborated by Kaufman and Rosenblum $[110,111]$ might prove quite useful in understanding the biphasic nature of many animal models and serve as a potential point of integration. In this model two styles of aversion reduction (initial active escape, subsequent passive emotional inhibition) may be seen as adaptive under different environmental circumstances. Activity represents initial attempts at reparation or escape. Passivity is a useful technique of conservation given an absence of other opitons. It is possible to conceive of a uni- or multidimensional mapping of depression models along a continuum of disrupted adaptation. A primary dimension may be active vs passive coping. Thus, for instance, it may be possible to conceive of the models of Porsolt, Seligman, and Hatotani at one end of this dimension, and acute responses to shock or separation at the 
other end. If more than one dimension is considered then this primary dimension may be divided into cognitive, affective, or motor disturbances. Further investigations might clarify a number of issues including whether initial agitation is directly related to the agitation of clinical depression and whether subsequent stress related behavioral depression is analogous to depressive retardation.

As noted, there is a clear need for a continuing technical dialogue between clinical researchers and laboratory based experimenters. It may be noted in conclusion that current developments in clinical research suggest a number of strategies which may be of potential use in testing established models or creating new ones. Studies on psychoendocrine, sleep, motor, and biochemical abnormalities are all possible based upon clinical studies. While we have noted their potential utility there has yet to be a thorough application of many of these procedures. Clearly if models involving these sorts of disturbances can be found, they offer a means of further clarifying the mechanisms of clinical disorders, and therefore of better understanding depression.

\section{ACKNOWLEDGEMENTS}

Supported in part by grant MH 31588 to Dr. B. J. Carroll with R. J. Katz as co-investigator. Dr. Katz is a Sloan Foundation Fellow in Neuroscience. The comments of K. A. Roth are acknowledged with gratitude. Editorial assistance was provided by A. Feingold.

\section{REFERENCES}

1. Abramson, L. Y. and M. E. P. Seligman. Modelling psychopathology in the laboratory: History and rationale. In: Psychopathology: Experimental Models, edited by J. D. Maser and M. E. P. Seligman. San Francisco: Freeman, 1977, pp. $1-27$.

2. Abramson, L. Y., M. E. P. Seligman and J. D. Teasdale. Learned helplessness in humans: Critique and reformulation. J. abnorm. Psychol. 87: 49-74, 1978.

3. Ackerman, S. H., M. A. Hofer and W. Weiner. Age at maternal separation and gastric erosion susceptibility in the rat. Psychosom. Med. 37: 180-184, 1975.

4. Achor, R. W. P., N. O. Hanson and R. W. Gifford. Hypertension treated with Rauwolfia serpentina (whole root) and with reserpine. J. Am. Med. Ass. 159: 841-845, 1955.

5. Akiskal, H. S. and W. McKinney. Overview of recent research in depression. Archs Gen. Psychiat. 32: 285-305, 1975.

6. Altenor, A. and E. A. Devoe. The effects of D, L parachlorophenylalanine on learned helplessness in the rat. Behav. Biol. 20: 111-115, 1977.

7. Anderson, D. C., C. R. Crowell, C. L. Cunningham and J. V. Lupo. Behavior during shock exposure as a determinant of subsequent interference with subsequent escape-avoidance learning in the rat. J. exp. Psychol., Anim. Behav. Proc. 5: 243-257, 1979.

8. Anderson, D. C., C. Koehn, C. Crowell and J. V. Lupo. Different intensities of unsignalled inescapable shock treatments as determinants of nonshock motivation open field behavior: A resolution of disparate results. Physiol. Behav. 17: 391-394, 1976.

9. Anisman, H., D. deCatanzaro and G. Remington. Escape performance following exposure to inescapable shock: Deficits in motor response maintenance. J. Exp. Psychol. Anim. Behav.Proc. 4: 192-218, 1978

10. Anisman, H., L. Grimmer, J. Irwin, G. Remington and L. S. Sklar. Escape performance after inescapable shock in selectively bred lines of mice: Response maintenance and catecholamine activity. J. comp. physiol. Psychpl. 93: 229-241, 1979.

11. Ainsman, H., A. Pizzino and L. S. Sklar. Coping with stress, norepinephrine and escape performance. Brain Res. 191: 583588,1980

12. Anisman, H., G. Remington and L. S. Sklar. Effect of inescapable shock on subsequent escape performance. Catecholaminergic and cholinergic mediation of response initiation and maintenance. Psychopharmacology 61: 107-124, 1979.

13. Anisman, H., A. Suissa and L. S. Sklar. Escape deficits induced by uncontrollable stress: Antagonism by dopamine and norepinephrine agonists. Behav. Neural Biol. 28: 34-47, 1980.

14. Anisman, H. and T. G. Waller. Facilitative and disruptive effect of prior exposure to shock on subsequent avoidance performance. J. comp. physiol. Psychol. 78: 113-122, 1972.

15. Askew, B. M. and A. Simple. Screening procedure for imipramine-like anti-depressant agents. Life Sci. 2: 725-730, 1963.
16. Ayres, J. J. B., J. O. Benedict and E. J. Witcher. Systematic manipulation of individual events in a truly random control in rats. J. comp. physiol. Psychol. 88: 97-103, 1975.

17. Babington, R. G. and P. W. Wedeking. The pharmacology of seizures induced by sensitization with low intensity brain stimulation. Pharmac. Biochem. Behav. 1: 461-467, 1973.

18. Bakwin, H. Loneliness in infants. Am. J. Dis. Child. 63: 30-40, 1942.

19. Baltzer, V. and L. Weiskrantz. Antidepressant agents and reversal of diurnal activity cycles in the rat. Biol. Psichiar. 10: 199-209, 1975.

20. Barnett, A., R. I. Taber and R. E. Roth. Activity of antihistamines in laboratory antidepressant tests. Int. J. Pharmac. 8: 73-79, 1969.

21. Beatty, W. W. Failure to observe learned helplessness in rats exposed to inescapable footshock. Bull. Psychon. Soc. 13: 272-273, 1979.

22. Beck, A. T. Depression. Philadelphia: University of Pennsylvania Press, 1967.

23. Behrend, E. R. and M. E. Bitterman. Sidman avoidance in the fish. J. exp. Analysis Behav. 13: 229-242, 1963.

24. Berendsen, H., B. E. Leonard and H. Rigter. The effect of psychotropic drugs on the DOPA potentiation test in mice. $\mathrm{Br}$. J. Pharmac. 52: 432-433, 1974.

25. Berger, F. M. Depression and antidepressant drugs. Clin. Pharmac. Ther. 18: 241-248, 1975.

26. Bernstein, S. and M. R. Kaufmann. A psychological analysis of apparent depression following Rauwolfia therapy. J. Mt. Sinai Hosp. 27: 525-530, 1960.

27. Bernstein, B. and C. N. Latimer. Behavioral facilitation: the interaction of imipramine and desipramine with amphetamine, alpha-pipradol, methylphenidate and thozalinone. Psychopharmacologia 12: 338-345, 1968.

28. Blackwell, R. E. and R. Guillemin. Hypothalamic control of adrenohypophyseal secretions. A. Rev. Physiol. 35: 357-390, 1973.

29. Blanchard, R. J., M. J. Kelley and D. C. Blanchard. Defensive reactions and exploratory behavior in rats. J. comp. physiol. Psychol. 87: 1129-1133, 1974.

30. Boissier, J. R., J. Fichelle-Pagny and P. Simon. Antireserpine chez le souris de l'imipramine de l'amitriptyline et de leurs derives mons desmethylles therapiezi. Therapie 21: 109, 1966.

31. Bowlby, J. Attachment and Loss, Vol. I. New York: Basic Books, 1969.

32. Bracewell, R. J. and A. H. Black. The effects of restraint and non-contingent preshock on subsequent escape learning in the rat. Learn. Motivat. 5: 53-69, 1974.

33. Braud, W., B. Wepmann and D. Russo. Task and species generality of the "helplessness" phenomenon. Psychon. Sci. 16: $154-155,1969$.

34. Brett, C. W. The generality of learned helplessness theory: effect of electroconvulsive shock. Doctoral Dissertation, Virginia Polytechnic Institute, Blacksburg, VA, Xerox University Microfilms, 77-22056, 1977. 
35. Buchwald, A. M., J. C. Coyne and L. S. Cole. A criticial evaluation of the learned helplessness model of depression. $J$. $a b$ norm. Psychol. 86: 180-193, 1978.

36. Burdette, D. R., D. S. Krantz and A. Amsel. Effects of inescapable shock in the rat: Learned helplessness or response competition. Bull. Psychon. Soc. 6: 96-98, 1975.

37. Cairncross, K. D., B. Cox, C. Forster and A. F. Wren. Olfactory projection systems drugs and behavior: A review. Psychoneuroendocrinology 4: 253-272, 1979.

38. Carlsson, A., M. Lindquist and T. Magnusson. 3,4-Dihydroxyphenylalanine and 5-hydroxytryptophan as reserpine antagonists. Nature 180: 1200, 1957.

39. Cariton, P. L. Potentiation of the behvioral effects of amphetamine by imipramine. Psychopharmacologia 2: 364-367, 1961.

40. Carlton, P. L. Some effects of scopolamine, atropine, and amphetamine in three behavioral situations. Pharmacologist 3: 60, 1961.

41. Carroll, B. J. Review of clinical research strategies in affective illness. In: Psychobiology of Depression, edited by J. Mendels. New York: Spectrum, 1975, pp. 143-159.

42. Carroll, B. J. Psychiatric disorders and steroids. In: Neuroregulators and Psychiatric Disorders, edited by E. Usdin, D. Hamburg and J Barchas. New York: Oxford University Press, 1977, pp. 276-283.

43. Carroll, B. J., G. C. Curtis and J. Mendels. Neuroendocrine regulation in depression. I. Limbic system-adrenal cortical dysfunction. Archs gen. Psychiat. 33: 1039-1044, 1976.

44. Carroll, B. J., G. C. Curtis and J. Mendels. Neuroendocrine regulation in depression. II. Discrimination of depressed from non-depressed patients. Archs gen. Psychiat. 33: 1051-1058, 1976.

45. Carroll, B. J. and J. Mendels. Neuroendocrine regulation in affective disorders. In: Hormones, Behavior and Psychopathology, edited by E. J. Sachar. New York: Raven Press, 1976, pp. 193-224.

46. Carroll, B. J. and P. T. Sharp. Rubidium and lithium: Opposite effects on amine-mediated excitement. Science 172: 1355-1357, 1971.

47. Chen, J. S. and A. Amsel. Prolonged, unsignalled inescapable shocks increase persistence in subsequent appetitive instrumental learning. Anim. Learn. Behav. 5: 377-385, 1977.

48. Coe, C. L. and S. P. Mendoza. Mother-infant attachments in the squirrel monkey: Adrenal response to separation. Behav. Biol. 22: 256-263, 1978.

49. Costello, C. G. A critical review of Seligman's laboratory experiments on learned helplessness and depression in humans. J. abnorm. Psychol. 87: 21-31, 1978.

50. Crowell, C. R. and D. C. Anderson. Shuttle interference effects in the rat depend upon activity during prior shock: A replication. Bull. Psychon. Soc. 14: 413-416, 1979.

51. Day, M. D. and M. J. Rand. Awakening from reserpine sedation by alpha-methyl dopa. J. Pharm. Pharmac. 15: 631-632, 1963.

52. Denenberg, V. H. Open field behavior in the rat-what does it mean? Ann. N.Y. Acad. Sci. 159: 852-859, 1969.

53. Depue, R. A. and S. M. Monroe. Learned helplessness in the perspective of the depressive disorders: Conceptual and definitional issues. J, abnorm. Psychol. 87: 3-20, 1978.

54. Domenjoz, R. and W. Theobald. Zur Pharmakologie des Tofranil. Archs int. Pharmacodyn. 120: 450-489, 1959.

55. Dorworth, T. R. and J. B. Overmier. On learned helplessness: The therapeutic effects of electroconvulsive shocks. Physiol. Psychol. 5: 355-358, 1977.

56. Dubinsky, B., K. Karpowicz and M. Goldberg. Effects of tricyclic antidepressants on attack elicited by hypothalamic stimulation: Relation to brain biogenic amines. J. Pharmac. exp. Ther. 18: 550-552, 1973.

57. Dunstan, H. P. Clinical experience with reserpine (Serpasil): A controlled study. Ann. N.Y. Acad. Sci. 59: 136-140, 1954.

58. Duvoisin, R. C. and C. D. Marsden. Reversal of reserpine induced bradykinesia by alpha-methyldopa: New light on its modus operandi. Brain Res. 71: 178-182, 1974.
59. Engel, G. L. Anxiety and depression withdrawal: The primary effects of unpleasure. Int. J. Psychoanal. 43: 89-97. 1962.

60. Esser, A. J., S. J. Suomi and H. F. Harlow. Production and alleviation of depressive behaviors in monkeys. In: Psychopathology Experimental Models, edited by J. D. Maser and M. E. P. Seligman. San Francisco: W. Freeman and Co. 1978, pp. 131-174.

61. Everett, G. M., F. Will and A. Evans. The search for new antidepressant drugs. Fedn Proc. 23: 198, 1964.

62. Everett, G. M. The DOPA response potentiation test and its use in screening for antidepressant drugs. In: Antidepressant Drugs, edited by S. Garattini and M. N. G. Dukes. Amsterdam: Excerpta Medica Found., 1967, pp. 164-167.

63. Evoniuk, G. E., C. M. Kuhn and S. M. Schanberg. The effect of tactile stimulation on serum growth hormone and tissue ornithine decarboxylase activity during maternal deprivation in rat pups. Communs Psychopharmac. 3: 363-370, 1979.

64. Extein, I., A. L. C. Pottash, M. S. Gold, D. R. Sweeney, D. M. Martin and F. R. Goodwin. Deficient prolactin response to morphine in depressed patients. Am.J. Psychiat. 137: 845-846, 1980.

65. Filaretov, A. A. The afferent input and functional organization of the hypothalamus in reactions regulating pituitary-adrenal cortical reactivity. Brain Res. 107: 39-54, 1976.

66. Freda, J. S. and S. B. Klein. Generality of the failure to escape (helplessness) phenomena in rats. Anim. Learn. Behav. 4: 401-406, 1976

67. Frize, E. D. Mental depression in hypertensive patients treated for long periods with large doses of reserpine. N. Engl.J. Med. 251: 1006-1008, 1954.

68. Fuxe, K., S. O. Ogren, B. J. Everitt, L. F. Agnati, P. Eneroth J. A. Gustafson, G. Jonsson, P. Skett and A. C. Holm. The effect of antidepressant drugs of the imipramine type on various monoamine systems and their relation to changes in behavioral and neuroendocrine function. In: Depressive Disorders, edited by S. Garattini and F. K. Schattauer. New York: Volag, 1977, pp. 67-94.

69. Garber, J. and S. P. Hollon. Universal versus personal helplessness in depression. Belief in uncontrollability or incompetence. J. abnorm. Psychol. 89: 56-66, 1980.

70. Garzon, J., J. A. Fuentes and J. Del Rio. Antidepressants selectively antagonize the hyperactivity induced in rats by long-term isolation. Eur. J. Pharmac. 59: 297-302, 1979.

71. Glass, D. C. and J. E. Singer. Urban Stress-Experiments on Noise and Social Stressors. New York: Academic Press, 1972.

72. Glazer, H. I. and J. M. Weiss. Long term interference effect: An alternative to learned helplessness. J. exp. Psychol. Anim. Behav. Proc. 2: 203-213, 1976.

73. Goldstein, K. The Organism. New York: American, 1939.

74. Goodwin, F. K. and W. E. Bunney, Jr. Depression following reserpine: A reevaluation. Semin. Psychiat. 3: 435-448, 1971.

75. Grabowska, M., L. Antkiewicz and J. Mechaluk. The influence of LSD on locomotor activity in reserpinized mice. Pol. J. Pharmac. Pharm. 26: 499-504, 1974.

76. Greene, W. A. Disease response to life stress. J. Am. Med. Womens Assoc. 20: 133-140, 1965.

77. Greene, W. A., S. Goldstein and A. J. Moss. Psychosocial aspects of sudden death. Archs int, Med. 129: 725-731, 1972.

78. Hamburg, D. A., B. A. Hamburg and J. D. Barchas. Anger and depression: in perspective of behavioral biology. In: Parameters of Emotion, edited by L. Levi. New York: Raven Press, 1975.

79. Harlow, H. Learning to Love. San Francisco: Albion, 1973.

80. Harlow, H. F. Induction and alleviation of depressive states in monkeys. In: Ethology and Psychiatry, edited by N. F. White. Toronto: University of Toronto Press, 1974, pp. 197-204.

81. Harlow, H. F. and M. K. Harlow. Effects of various motherinfant relationships on rhesus monkey behaviors. In: Determinants of Infant Behavior, Vol. 4, edited by B. M. Foss. London: Methuen, 1969, pp. 15-36.

82. Hatotani, N., J. Nomura, T. Yamaguchi and I. Kitayama. Clinical experimental studies on the pathogenesis of depression. Psvchoneuroendocrinology 2: 115-130, 1977. 
83. Heinicke, C. M. Parental deprivation in early childhood: A predisposition to later depression. In: Separation and Depression, edited by J. P. Scott and E. C. Senay. Washington, D.C.: American Acad. Adv. Sci., 1973, pp. 141-161.

84. Hennessy, M. B., J. N. Kaplan, S. P. Mendoza, E. L. Lowe and $S$. Levine. Separation distress and attachment in surrogate reared squirrel monkeys. Physiol. Behav 23: 1017-1023, 1979.

85. Herman, B. and J. Panksepp. Effects of morphine and naloxone on separation distress and approach attachment: Evidence for opiate mediation of social affect. Pharmac. Biochem. Behav. 9: 213-220, 1978.

86. Hill, S. D., S. A. McCormack and W. A. Mason. Effect of artificial mothers and visual experience on adrenal responsiveness of infant monkeys. Devel. Psychobiol. 6: 421-429, 1973.

87. Hill, R. T. and D. H. Tedeschi. Animal testing and screening procedures in evaluating psychotropic drugs. In: An Introduction to Psychopharmacology, edited by R. H. Rech and K. E. Moore. New York: Raven Press, 1971, pp. 237-288.

88. Hinde, R. A. Mother-infant relations in rhesus monkeys. In: Ethology and Psychiatry, edited by N. F. White. Toronto: University of Toronto Press, 1974, pp. 29-47.

89. Hiroto, D. S. The relationship between learned helplessness and the locus of control. J. exp. Psychol. 102: 187-193, 1974.

90. Hiroto, D. S. and M. E. P. Seligman. Generality of learned helplessness in man. J. Pers. soc. Psychol. 31: 311-327, 1975.

91. Hofer, M. A. Physiological and behavioral processes in early maternal deprivation. In: CIBA Symposium 8: PhysiologyEmotion in Psychosomatic Illness, CIBA Foundation. Amsterdam: Elsevier, 1972, pp. 175-200.

92. Hofer, M. A. The effects of brief maternal separations on behavior and heart rate of two week old rat pups. Physiol. Behav. 10: 423-427, 1973.

93. Hofer, M. A. Physiological mechanisms for cardiac control by nutritional intake after early maternal separation in the young rat. Psychosom. Med. 37: 8-24, 1975.

94. Hofer, M. A. Studies on how early maternal separation produces behavioral change in young rats. Psychosom. Med. 37: 245-264, 1975.

95. Hoffman, H. S. and A. M. Rattner. A reinforcement model of imprinting: Implications for socialization in monkeys and men. Psychol. Rev. 80: 527-544, 1973.

96. Horovitz, Z. P. Psychoactive drugs and limbic system of the brain. Psychosomatics 6: 281-286, 1965.

97. Horovitz, Z. P. The relationship of the amygdala to the mechanism of action of two types of antidepressants. In: Recent Advances in Biological Psychiatry, edited by J. Wortis. New York: Plenum Press, 1966.

98. Horovitz, Z. P., J. J. Piala, J. P. High, J. C. Burke and R. C. Leaf. Effects of drugs of the mouse-killing (muricide) test and its relationship to amygdaloid function. Int. J. Neuropharmac. 5: $405-411,1966$.

99. Horovitz, Z. P., R. Ragozzino and R. C. Leaf. Selective block of rat mousekilling by antidepressants. Life Sci. 4: 1909-1912, 1965.

100. Huesmann, L. R. Cognitive processes and models of depression. J. abnorm. Psychol. 86: 194-198, 1978.

101. Hurdina, P. D., P. Von Kulmiz and R. Stretch. Pharmacological modification of experimental depression in infant macaques. Psychopharmacology 64: 89-93, 1979.

102. Irwin, J., A. Suissa and H. Anisman. Differential effects of inescapable shock on escape performance and discrimination learning in a water escape task.J. exp. Psychol. Anim. Behav. Proc. 6: $21-40,1980$.

103. Jackson, R. L., J. H. Alexander and S. F. Maier. Learned helplessness, inactivity vs associative deficits: Effects of inescapable shock on response choice escape learning. $J$. exp. Psychol. Animal Behav. Proc. 6: 61-20, 1980.

104. Jackson, R. L., S. F. Maier and P. M. Rappaport. Exposure to inescapable shock produces both activity and associative deficits in the rat. Learn. Motiv. 9: 69-98, 1978.
105. Jacobsen, E. The theoretical basis of the chemotherapy of depression. In: Depression: Proceedings of the Symposium at Cambridge. Sept. 1959, edited by E. B. Davies. New York: Cambridge University Press, 1964.

106. Jensen, $K$. Depressions in patients treated with reserpine for arterial hypertension. Acta psychiat. scand. 34: 195-204, 1959.

107. Jones, B. C. and D. L. Clark. Mother-infant separation in squirrel monkeys living in a group. Devel. Psychobiol. 6: 259 $269,1973$.

108. Katz, R. Lithium and the structure of exploratory behavior in the rat. Prog. Neuropsychopharmac, 4: 37-42, 1980.

109. Katzev, R. D. and S. V. Miller. Strain differences in avoidance conditioning as a function of classical CS-US contingency. $J$. comp. physiol. Psychol. 87: 661-671, 1974.

110. Kaufman, I. C. Mother infant separation in monkeys: An experimental model. In: Separation and Depression-Clinical and Research Aspects, No. 94, edited by J. P. Scott and E. C. Senay. Washington, D.C.: Am. Acad. Adv. Sci., 1973.

111. Kaufman, I. C. and L. A. Rosenblum. The reaction to separation in infant monkeys: Anaclitic depression and conservation-withdrawal. Psychosom. Med. 29: 648-675, 1967.

112. Kaufman, I. C. and A. J. Stynes. Depression can be induced in a bonnet macaque infant. Psychosom. Med. 40: 71-75, 1978.

113. King, D. L. A review and interpretation of some aspects of the infant mother relationships in mammals and birds. Psychol. Bull. 65: 143-155, 1966

114. King, J. A. Social relationships of the domestic guinea pig living under seminatural conditions. Ecology 37: 221-228, 1956.

115. Kline, D. F. Endogenomorphic depression-a conceptual and terminological revision. Archs gen. Psychiat. 31: 447-454. 1974.

116. Kline, D. F. and J. M. Davis. Diagnosis and Drug Treatment of Psychiatric Disorders. Baltimore: Williams and Wilkins, 1969.

117. Klinger, E., S. G. Barta and E. D. Kemble. Cyclic activity changes during extinction in rats: A potential model of depression. Anim. Learn. Behav. 2: 313-316, 1974.

118. Kraemer, G. W., W. T. McKinney, Jr., A. J. Prange, Jr., G. R. Breese, T. M. McMurray and J. Kemnitz. Isonaizid: behavioral and biochemical effects in rhesus monkeys. Life Sci. 19: $49-60,1976$.

119. Kupfer, D. J. REM latency: A psychobiological marker for primary depressive disease. Biol. Psychiat. 11: 160-164, 1976.

120. Kuhn, C. M., S. R. Butler and S. M. Schanberg. Selective depression of serum growth hormone during maternal deprivation in rat pups. Science 201: 1034-1036, 1978.

121. LaBarba, R. C., J. Martini and J. White. The effect of maternal separation on the growth of Ehrlich carcinoma in the balb/c mouse. Psychosom. Med. 21: 129-133, 1969.

122. LaBarba, R. C. and J. L. White. Maternal deprivation and the response to Ehrlich carcinoma in balb/c mice. Psychosom. Med. 33: 458, 1971.

123. LaBarba, R. C., J. M. Lazar and J. L. White. The effects of maternal separation, isolation and sex on the response to Ehrlich carcinoma in balb/c mice. Psychosom. Med. 34: 557559, 1972.

124. Lapin, I. P. Qualitative and quantitative relationships between the effects of imipramine and chlorpromazine on amphetamine group toxicity. Psychopharmacoloiga 3: 413-418, 1962.

125. Leff, M. J., J. F. Roatch and W. E. Bunney. Environmental factors preceding the onset of severe depressions. Psychiatry 33: 293-311, 1970.

126. Lemieux, G., A. Davigon and J. Genest. Depressive states during Rauwolfia therapy for Arterial hypertension: A report of 30 cases. Can. Med. Ass. J. 74: 522-526, 1956.

127. Lemberger, L., E. Sernathiger and R. Kuntzman. Effect of desmethylimipramine, iprindole and d,1 erythro-a(3,4dichlorophenyl) butylaminopropranalol on the metabolism of amphetamine. Biochem. Pharmac. 19: 3021-3028, 1970.

128. Leshner, A. I., R. Hofstein, D. Samuel and T. B. Van Wimersma-Greidanus. Intraventricular injection of antivasopressin serum blocks learned helplessness in rats. Pharmac. Biochem. Behav. 9: 889-892, 1978. 
129. Levine. S., C. L. Coe, W. P. Smotherman and J. N. Kaplan. Prolonged cortisol elevation in the infant squirrel monkey after reunion with mother. Physiol. Behav. 20: 7-10, 1973.

130. Levine, S. Physiological and behavioral effects of prior aversive stimulation (pre-shock) in the rat. Physiol. Behav. 10: 467-471, 1973.

131. Levis, D. J. Learned helplessness-a reply and an alternative S-R interpretation. J. exp. Psychol. Gen. 105: 47-65, 1976.

132. Levis, D. J. The learned helplessness effect on expectancy, discrimination deficit, or motivationally induced persistence. $J$. Res. Personal. 14: 158-169, 1980.

133. Lewis, J. K. and W. T. McKinney, Jr. Effects of electroconvulsive shock on the behavioral of normal and abnormal rhesus monkeys. Behav. Psychiat. 37: 687-693, 1976.

134. Lewis, J. K., W. T. McKinney, Jr., L. D. Young and G. W. Kraemer. Mother-infant separation in rhesus monkeys as a model of human depression-a reconsideration. Archs gen. Psychiat. 33: 699-705, 1976.

135. Looney, T. A. and P. S. Cohen. Retardation of jump up escape responding in rats pretreated with different frequencies of non-contingent electrical shock.J. comp. physiol. Psychol. 78: $317-322,1972$

136. Lynch, J. J. Psychophysiology and the development of social attachment. J. nerv. ment. Dis. 151: 231-244, 1970.

137. Maier, S. F. Failure to escape traumatic electric shock: Incompatible skeletal-motor responses or learned helplessness. Learn. Motiv. 1: 157-169, 1970.

138. Maier, S. F. Learned helplessness and the schedule-shift hypotheses. J. Res. Personal. 14: 170-186, 1980.

139. Maier, S. F., R. W. Albin and T. J. Testa. Failure to learn to escape in rats previously exposed to inescapable shock depends on nature of escape response.J. comp. physiol. Psychol. 85: 581-592, 1973

140. Maier, S. F. and M. E. P. Seligman. Learned helplessness: Theory and evidence. J. exp. Psychol. 105: 3-46, 1976.

141. Maier, S. F., D. J. Coon, M. A. McDaniel, R. L. Jackson and J. Gran. The time course of learned helplessness inactivity and nociceptive deficits in rats. Learn. Motiv. 10: 467-487, 1979.

142. Malec, D. and $Z$. Kleinrok. The spontaneous motility of rats after intraventricular injection of dopamine. Neuropharmaco/ogy 11: 331-336, 1972

143. McKinney, W. T., Jr. Biobehavioral models of depression in monkeys. In: Animal Models in Psychiatry and Neurology. edited by I. Hanin and E. Usdin. New York: Pergamon, 1977. pp. 117-126.

144. McKinney, W. T., Jr. and W. E. Bunney. Animal model of depression: Review of evidence and implications for research. Archs gen. Psychiat. 21: 240-248, 1969.

145. McKinney, W. T., S. J. Suomi and H. F. Harlow. New models of separation and depression in rhesus monkeys. In: Separation and Depression. edited by J. P. Scott and E. C. Senay. Washington, D.C.: Am. Assoc. Adv. Sci., 1973, pp. 53-69.

146. McReynolds, W. T. Learned helplessness as a schedule shift effect. J. Res. Personal. 14: 139-157, 1980.

147. McReynolds, W. T. Theories, research, and evidence of learned helplessness a reply to Levis and Maier. J. Res. Personal. 14: 187-195, 1980 .

148. Mendels, J. and A. Frazer. Brain biogenic amine depletion and mood. Archs gen. Psychiat. 30: 447-451, 1974.

149. Mikulka, P., P. Kendall, J. Constantine and L. Porterfield. The effect of Pavlovian CS + and CS on exploratory behavior. Psychonom. Sci. 27: 307-310, 1972.

150. Miller, R. A., R. A. Rosellini and M. E. P. Seligman. Learned helplessness and depression. In: Psychopathology: Experimental Models, edited by J. D. Maser and M. E. P. Seligman. San Francisco: Freeman, 1978, pp. 104-130.

151. Moran, P. W. and M. Lewis-Smith, Learned helplessness and response difficulty. Bull. Psychon. Soc. 13: 250-252, 1979.

152. Morpurgo, $C$. and W. Theobald. Influence and imipramine-like compounds and chlorpromazine on the reserpine hypothermia in mice and the amphetamine hyperthermia in rats. Med. pharmac. exp. 12: 1226, 1965.
153. Muller, J. C. Depression and anxiety occurring during Rauwolfia therapy. J. Am. Med. Ass. 159: 836-839, 1955.

154. Noirot, E. Ultrasounds in young rodents. 1. Changes in age in albino mice. Anim. Behav. 14: 459-462, 1966.

155. Noirot, E. Ultrasounds in young rodents. II. Changes with age in albino rats. Anim. Behav. 16: 129-134, 1968.

156. Oswald. I.. V. Brezinova and D. L. F. Dunleavy. On the slowness of action of tricyclic antidepressant drugs. Br. J. Psychiat. 120: 673-677. 1972

157. Overmeier, J. B. Interference with avoidance behavior: Failure to avoid traumatic shock. J. exp. Psychol. 78: 340-343. 1968.

158. Padilla, A. M., C. Padilla, T. Keterer and D. Giacalone. Inescapable shocks and subsequent avoidance conditioning in the goldfish carassius auratus. Psychon. Sci. 20: 295-296, 1970.

159. Panksepp, J., J. B. Herman, R. Connor, P. Bishop and J. P. Scott. The biology of social attachments: Opiates alleviate separation distress. Biol. Psychiat. 13: 607-618. 1978.

160. Panksepp, J., T. Vilberg, N. J. Bean. D. H. Coy and A. J. Kastin. Reductions of distress vocalization in chicks by opiate-like peptides. Brain Res. Bull. 3: 663-667. 1978.

161. Peterfy, G., E. J. Pinter and C. J. Patee. Psychosomatic aspects of catecholamine depletion: Comparative studies of metabolic, endocrine and affective changes. Psichomeuroendocrinology 1: 243-254, 1976.

162. Petty, F. and A. D. Sherman. Reversal of learned heiplessness by imipramine. Communs Psychopharmac, 3: 371-374. 1979.

163. Plaut, S. M. and J. M. Davis. Effects of mother litter separation on survival growth and brain amino acid levels. Physiol. Behai. 8: 43-51, 1972.

164. Plaut, S. M., A. Thal, E. E. Haynes and J. E. Wagner. Maternal deprivation in the rat: Prevention of mortality by nonlactating adults. Psychosom. Med. 36: 311-320, 1974.

165. Pollard, I.. B. M. White, J. R. Bassett and K. Cairncross. Plasma glucocorticoid elevation and desyncrhonization of the estrus cycle following unpredictable stress in the rat. Behar. Biol. 14: 103-108, 1975.

166. Porsolt, R. D., G. Anton, N. Blavet and M. Jalfre. Behavioral despair in rats. a new model sensitive to antidepressant treatments. Eur. J. Pharmac. 47: 379-391, 1978.

167. Porsolt, R. D., A. Bertin, N. Blavet, M. Deniel and M. Jalfre Immobility induced by forced swimming in rats: Effects of agents which modify central catecholamine and serotonin activity. Eur. J. Pharmac. 57: 201-210, 1979.

168. Porsolt, R. D., A. Bertin and M. Jalfre. Behavioral despair in rats and mice: Strain differences and the effects of imipramine. Eur. J. Pharmac. 51: 291-294, 1978.

169. Porsolt, R. D., M. LePichon and M. Jalfre. Depression: A new animal model sensitive to antidepressant treatments. Nature 266: 730-732, 1977

170. Porter, R. H., J. C. Berryman and C. Fullerton. Exploration and attachment behavior in infant guinea pigs. Behavior 45: 312-322, 1973.

171. Prange, A. J. The pharmacology and biochemistry of depression. Dis. Nerv. Syst. 25: 217-221, 1964

172. Preston, D. G., R. P. Baker and B. M. Seay. Mother-infant separation in Patas monkeys. Devel. Psychol. 3: 298-306, 1970.

173. Racinskas, J. R. Maladaptive consequences of loss of control over aversive events. Doctoral Dissertation. Waterloo. Ontario, 1971.

174. Rech, R. H. and K. E. Moore. An Introduction to Psychepharmacology. New York: Raven Press. 1971.

175. Reite, M. Maternal separation in infant monkeys: A model of depression. In: Animal Models in Psychiarry and Neurology. edited by I. Hanin and E. Usdin. New York: Pergamon Press, 1977, pp. 127-139.

176. Reite, M. I., C. Kaufman, J. D. Pauley and A. J. Stynes. Depression in infant monkeys: Physiological correlates. Psychosom. Med. 36: 363-367, 1974.

177. Rescorla, R. A. and A. Wagner. A theory of Pavlovian conditioning variations in the effectiveness of reinforcement and non-reinforcement. In: Classical Conditioning. II. Theory and Research, edited by A. H. Black and W. P. Prokasy. New York: Appleton-Century-Crofts, 1972. 
178. Rheingold, H. L. and C. O. Eckerman. Familiar social and non-social stimuli and the kitten's response to a strange environment. Devel. Psychobiol. 4: 78-89, 1971.

179. Rie, H. E. Depression in childhood. J. Am. Acad. Child Psychiat. 5: 653-685, 1966.

180. Robertson, J. and J. Bowlby. Responses of young children to separation from their mothers. Courr. Cent. int. Enf. 2: 131$162,1952$.

181. Robertson, J. and J. Robertson. Young children in brief separation: A fresh look. Psychoanal. Study Child 26: 264-316, 1971.

182. Rosenblatt, J. S., G. Turkersitz and T. C. Schneirla. Development of home orientation in newly born kittens. Trans. N. Y. Acad. Sci. 31: 231-250, 1969.

183. Roth, S. and L. Kubal. Effects of non-contingent reinforcement on tasks of differing importance-facilitation and learned helplessness. J. Pers. soc. Psychol. 32: 680-691, 1975.

184. Rotter, J. B. Generalized expectancies for internal vs. external control of reinforcement. Psychol. Monogr. 80: 609, 1966.

185. Rotter, J. B. Social Learning and Clinical Psychology. New York: Prentice Hall, 1954.

186. Rush, J. and J. Mendeis. Effects of lithium chloride on muricidal behavior in rats. Pharmac. Biochem. Behav. 3: 795-797, 1975.

187. Ruther, E., M. Achenheil and N. Matusek. Beitrag zum Noradrenalin- und Serotonin-Stoffwechsel im Ratterhirn nach Stress-Zustanden. Arzneimittel-Forsch. 16: 261-263, 1966.

188. Ruther, E., M. Achenheil and N. Matusek. Amine metabolism in CNS after stress-situation. Activitas nerv. sup. 8: 416-417. 1966.

189. Sackett, G. P. Monkeys reared in visual isolation with pictures as visual input: Evidence for an innate releasing mechanism. Science 154: 1468-1472, 1966.

190. Salama, A. and M. E. Goldberg. Neurochemical effects of imipramine and amphetamine in aggressive mouse-killing (muricidal rats). Biochem. Pharmac. 19: 2023, 1970.

191. Sanghvi, I., E. Bindler and S. Gershon. The evaluation of a new animal method for the prediction of clinical antidepressant activity. Life Sci. 8: 99-106, 1969.

192. Sanghvi, I. and S. Gershon. The evaluation of central nervous system stimulants in a new laboratory test for antidepressants. Life Sci. 8: $449-457,1969$.

193. Sanghvi, I. and S. Gershon. Similarities between behavioral and pharmacological actions of yohimbine and 5-hydroxytryptophan in the conscious dog. Eur. J. Pharmac'. 11: 125-129. 1970.

194. Schildkraut, J. J. The catecholamine hypothesis of affective disorders: A review of supporting evidence. Am. J. Psychiat. 122: 509-522, 1965

195. Scott, J. P. Modification of the development of emotional behavior. Proc, of 5th Int. Cong. Coll. Internatl. Neuropsychopharmacol. Excerpta Medica 129: 774-780, 1966.

196. Scott, J. P., J. M. Stewart and V. DeGhett. Separation in infant dogs: Emotional response and motivational consequences. In: Separation and Depression, edited by J. P. Scott and E. C. Senay. Washington, D.C.: Am. Assoc. Adv. Sci., 1973, pp. 3-32.

197. Seligman, M. E. P. Helplessness. San Francisco: W. H. Freeman, 1975.

198. Seligman, M. E. P. and G. Beagley. Learned helplessness in the rat. J. comp. physiol. Psychol. 88: 534-541, 1975.

199. Seligman, M. E. P.. S. F. Maier and J. Geer. The alleviation of learned helplessness in the dog. J. abnorm. Psychol. 73: 756$762,1968$.

200. Seligman, M. E. P., R. A. Rosellini and M. J. Kozak. Learned helpiessness in the rat: Time course immunization and reversibility. J. comp, physiol. Psychol. 88: 542-547, 1975.

201. Senay, E. C. Toward an animal model of depression. $J$. psychiat. Res. 4: 65-71, 1966.

202. Seward, J. P. and G. L. Humphrey. Avoidance learning as a function of pretraining in the cat.J. comp. physiol. Psychol. 63: $338-341,1967$.
203. Shapiro, L. J. and K. L. Garretson. Avian attachment behavior: An extension of Cairns theory of mammalian social attachments. J. biol. Psychol. 20: 9-12, 1979.

204. Shurman, A. J. and R. D. Katzev. Escape avoidance responding in rats depends on strain and number of inescapable preshocks. J. comp. physiol. Psychol. 88: 548-553, 1975.

205. Sigg, E. D. The pharmacodynamics of imipramine. In: The First Hahnemann Symposium on Psychosomatic Medicine, edited by J. Nodine and J. H. Moyer. Philadelphia: Lea and Fibiger, 1962, p. 671.

206. Sigg, E. B., L. Gyermek and R. T. Hill. Antagonism to reserpine induced depression by imipramine, related psychoactive drugs and some autonomic agents. Psychopharmacologia 7: $144-149,1965$.

207. Sigg, E. B. and R. T. Hill. The effect of imipramine on central adrenergic mechanisms. In: Neuro-Psycho-Pharmacology; edited by H. Brill. Amsterdam: Excerpta Medica Foundation. 1967, pp. 367-372.

208. Simon, P. and J. M. Lwoff. Criteres de selection des antidepresseurs. In: The Present State of Psvchotropic Drugs. edited by $A$. Cerletti and F. J. Bovet. Amsterdam: Excerpta Medica Foundation, 1969, pp. 184-189.

209. Smirk, F. H. and E. G. McQueen. Comparison of rescinnamine and reserpine as hypotensive agents. Lancet 269: 115-116. 1955.

210. Smotherman, W. P., L. E. Hunt, L. M. McGinnis and S. Levine. Mother-infant separation in group living rhesus macaques-a hormonal analysis. Devel. Psychobiol. 12: 211218, 1979.

211. Spencer-Booth, Y. and R. A. Hinde. Effects of six day separation from mother on 19-32 week old rhesus monkeys. Anim. Behav. 19: 174-191, 1971.

212. Spencer-Booth, Y. and R. A. Hinde. The effects of 13 days maternal separation on infant rhesus monkeys compared with those of shorter and repeated separations. Anim. Behav, 19: 595-605, 1971.

213. Spitz, R. A. Anaclitic depression. Psychoanal. Stud. Child 2: 313-347, 1946

214. Stein, L. Effects and interactions of imipramine. chlorpromazine, reserpine and amphetamine on self-stimulation: Possible neurophysiological basis of depression. In: Recen Advances in Biological Psychiatry, Vol. 4. New York: Plenum Press, 1962, pp. 288-309.

215. Stein. L. New methods for evaluating stimulants and antidepressants. In: Sixth Hahnemann Sympos. Psychosom. Med., edited by J. H. Nodine. Philadelphia: Lea and Fibiger, 1967. p. 297

216. Stein, L. and J. Seifter. Possible mode of the antidepressant action of imipramine. Science 134: 286-287, 1961.

217. Stone, E. A. Swim-stress-induced inactivity, relation to body temperature and brain norepinephrine, and effects of d-amphetamine. Psychosom. Med. 32: 51-59, 1970.

218. Stone, E. A. Behavioral and neurochemical effects of acute swimming stress are due to hypothermia. Life Sci. 9: 877-888. 1970.

219. Sulser, F., J. S. Watts and B. B. Brodie. Blocking of reserpine action by imipramine, a drug devoid of stimulatory properties in normal animals. Fedn Proc. 20: 321, 1961.

220. Suomi, S. J. Factors affecting responses to social separation in rhesus monkeys. In: Animal Models in Human Psvchobiology, edited by G. Serban and A. Kling. New York: Plenum Press. 1976, pp. 9-26.

221. Suomi, S. J., M. L. Collins, H. F. Harlow and G. C. Ruppenthal. Effects of maternal and peer separation on young monkeys. J. child Psychol. Psychiat. 17: 101-112, 1976.

222. Suomi, S. J., C. D. Eisele, S. A. Grady, H. F. Harlow. Depression in adult monkeys following separation from nuclear family environment. J. abnorm. Psychol. 84: 576-578, 1975.

223. Suomi, S. J. and H. F. Harlow. Apparatus conceptualization for psychopathological research in monkeys. Behav. Res. Meth. Instrum. 1: 247-250, 1969. 
224. Suomi, S. J. and H. F. Harlow. The facts and functions of fear. In: Emotion and Anxiety, edited by M. Zuckerman and C. D. Spielberger. Hillsdale, NJ: Erlbaum Press, 1976, pp. 3-34.

225. Suomi, S. J. and H. A. Harlow. Production and alleviation of depressive behaviors in monkeys. In: Psychopathology: Experimental Models, edited by J. D. Maser and M. E. P. Seligman. San Francisco: W. H. Freeman, 1978, pp. 131-173.

226. Suomi, S. J., S. F. Seaman, J. K. Lewis, R. D. DeLizio and W. T. McKinney, Jr. Effects of imipramine treatment of separation induced social disorders in rhesus monkeys. Archs gen. Psychiat. 35: 321-325, 1978.

227. Thomas, E. and L. DeWald. Experimental neurosisneuropsychological analysis. In: Psychopathology: Experimental Models, edited by J. D. Maser and M. E. P. Seligman. San Francisco: W. H. Freeman, 1978, pp. 214-231.

228. Tobach, E. and P. S. Gold. Behavior of the guinea pig in the open field situation. Psychol. Rept. 18: 415-425, 1966.

229. Valzelli, L. and S. Bernasconi. psychoactive drug effect on behavioral changes induced by prolonged socio-environmental deprivation in rats. Psychol. Med. 6: 271-276, 1976.

230. Vernier, V. G., H. M. Hanson and C. A. Stone. The pharmacodynamics of amitriptyline. In: First Hahnemann Symp. Psychosom. Med., edited by J. H. Nodine and J. H. Moyer. Philadelphia: Lea and Fibiger, 1962, pp. 683-690.

231. Wagner, H. R., III, T. L. Hall and I. L. Cote. The applicability of inescapable shock as a source of animal depression. J. gen. Psychol. 96: 313-318, 1977.

232. Wehr, T. A., A. Wirz-Justice, F. K. Goodwin, W. Duncan and J. C. Gillin. Phase advance of the circadian sleep-wake cycle as an antidepressant. Science 206: 710-713, 1979.

233. Weiss, J. M. and H. I. Glaser. The effects of acute exposure to stressors on subsequent avoidance behavior. Psychosom. Med. 37: 499-521, 1975.
234. Weiss, J. M., H. I. Glaser and L. A. Pohorecky. Coping behavior and neurochemical changes-an alternative explanation for the original "learned helplessness" experiments. In: Animal Models in Human Psychobiology, edited by G. Serban and A. Kling. New York: Plenum Press, 1976, pp. 141-170.

235. Weiss, J. M., H. I. Glaser, L. A. Pohorecky, J. Brick and N. E. Miller. Effects of chronic exposure to stressors on avoidanceescape behaviors and on brain norepinephrine. Psychosom. Med. 37: 522-534, 1975.

236. Weissman, $O$. Interaction effects of imipramine and d-amphetamine on conditioned avoidance. Pharmacologist 3: 60 , 1961.

237. Willis, M. H. and P. H. Blaney. Three tests of the learned helplessness model of depression. J. abnorm. Psychol. 87: 131-136, 1978.

238. Wilson, W. J. and L. L. Butcher. A potential shock reducing contingency in the back shock technique: Implications for learned helplessness. Anim. Learn. Behav. 8: 435-440, 1980.

239. Wirz-Justice, A. and J. Arendt. Diurnal, menstrual cycle and seasonal indole rhythms in man and their modification in affective disorders. Proc. World Congr. Psychty. . Barcelona, 1978, in press.

240. Wolpe, J. Neurotic depression-experimental analog-clinical syndromes and treatment. Am. J. Psychother. 25: 362-368, 1971.

241. Woodward, W. T. and M. E. Bitterman. Pavlovian analysis of avoidance conditioning in the goldfish. J. comp. physiol. Psychol. 82: 123-129, 1973.

242. Wortman, C. B. and L. Dintzer. Is an attributional analysis of the leamed helplessness phenomenon viable? $J$. abnorm. Psychol. 87: 75-90, 1978.

243. Young, L. D., S. J. Suomi, H. F. Harlow and W. T. McKinney, Jr. Early stress and later response to separation. Am. J. Psychiat. 130: 400-405, 1973. 